\title{
Platelet Rich Plasma Regulates Wnt/Beta-Catenin Signal Pathway in Rabbit Chondrocytes by Mediating Interleukin 1 Beta
}

\author{
XH ZUO ${ }^{1,2}, \mathrm{~N} \mathrm{SUN}^{3}$, P. XIE ${ }^{4}$, L. WANG ${ }^{5}, \mathrm{YN} \mathrm{SI}^{1}, \mathrm{H}$. G. BAO ${ }^{1 *}$ AND Q. X. ZHANG ${ }^{2 *}$ \\ ${ }^{1}$ Department of Anesthesiology, Nanjing First Hospital, Nanjing Medical University, Nanjing, 210006, ${ }^{2}$ Department of Pain \\ Management, ${ }^{3}$ Department of Interventional Radiology, ${ }^{4}$ Department of Neurosurgery, ${ }^{5}$ Department of Anesthesiology, The \\ Affiliated Huai'an Hospital of Xuzhou Medical University and The Second People's Hospital of Huai'an, Huai'an, 223002, \\ China
}

\section{Zuo et al.: PRP Regulates Wnt/B-Catenin Signal Pathway in Rabbit Chondrocytes}

\begin{abstract}
It was reported that platelet rich plasma can reduce the degeneration of articular cartilage. The purpose of this study was to investigate the effect of platelet rich plasma on Wnt/beta-catenin signal transduction in rabbit chondrocytes. Platelet rich plasma was prepared from the ear vein blood of 3-mo old New Zealand white rabbits. Chondrocytes were isolated from knee cartilage and cultured. The cell identification and the effect of platelet rich plasma on the viability of chondrocytes were measured by the C-terminal telopeptide II and proteoglycan staining. Chondrocytes were divided into 5 groups, control group, interleukin-1 beta group, platelet rich plasma (100 $x$ dilutions) group, Dickkopf WNT signaling pathway inhibitor 1 (100 $\mathrm{ng} / \mathrm{mL}$ ) group and Dickkopf WNT signaling pathway inhibitor 1+platelet rich plasma group. After being treated with interleukin-1 beta $(50 \mu \mathrm{L}, 10 \mu \mathrm{g} / \mathrm{mL})$ for $24 \mathrm{~h}$, the morphology of chondrocytes was observed by an electron microscope. The levels of C-terminal telopeptide II and cartilage oligomeric matrix protein in the culture medium were determined by enzyme linked immunosorbent assay. The messenger RNA and protein expression levels of Wnt-1, beta-catenin and glycogen synthase kinase 3 beta were detected by Real-time polymerase chain reaction and Western blot respectively. Platelet rich plasma promotes the proliferation of chondrocytes. The chondrocytes in the interleukin-1 beta group showed an ultrastructural abnormality, which was not obvious in platelet rich plasma group, Dickkopf WNT signaling pathway inhibitor 1group, and Dickkopf WNT signaling pathway inhibitor $1+$ platelet rich plasma group. The concentrations of $\mathrm{C}$-terminal telopeptide II and cartilage oligomeric matrix protein in the interleukin-1 beta group were higher than those in the control group, platelet rich plasma group, Dickkopf WNT signaling pathway inhibitor 1group and Dickkopf WNT signaling pathway inhibitor 1+platelet rich plasma group. Compared with the control group, platelet rich plasma group, Dickkopf WNT signaling pathway inhibitor 1group and Dickkopf WNT signaling pathway inhibitor 1+platelet rich plasma group, the expression of Wnt1 and beta-catenin was higher and the level of glycogen synthase kinase 3 beta was lower in the interleukin-1 beta group. Platelet rich plasma may protect interleukin-1 beta activated chondrocytes by inhibiting Wnt/beta-catenin signal.
\end{abstract}

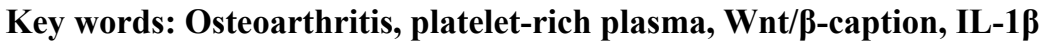

Osteoarthritis (OA) was a common degenerative joint disease and its incidence was positively correlated with age $^{[1]}$, which was also the main cause of disability in the middle aged and elderly ${ }^{[2,3]}$. However, there was no effective treatment strategy for OA; the drug treatments can only relieve the joint pain, not cure. At present, the best choice for the advanced OA patients was the joint replacement ${ }^{[4,5]}$. Therefore, there is an urgent need for new therapeutic drugs to treat OA.
Degeneration, wear and degeneration of the cartilage were the main pathological features of OA. The apoptosis of chondrocytes ${ }^{[6,7]}$ and the regulation of the bone metabolism and cartilage homeostasis played an important role in the development of OA, which was controlled by the classical $\mathrm{Wnt} / \beta$-catenin signal pathway ${ }^{[8]}$. Inflammatory cytokines can destroy the internal environment stability of the cartilage, for example, interleukin-1beta (IL-1 $\beta$ ) was an effective

*Address for correspondence

E-mail: qianxizhan_cn@163.com 
inducer of the cartilage matrix degradation ${ }^{[9]}$. At the same time, the inhibition of $\mathrm{Wnt} / \beta$-catenin signal can block the IL-1 $\beta$ induced cartilage degradation ${ }^{[10]}$. Therefore, IL-1 $\beta$ was considered to activate the $W n t / \beta$-catenin signal in chondrocytes and induce the chondrocyte apoptosis ${ }^{[11]}$ by releasing the C-terminal telopeptide II (CTX-II) and cartilage oligomeric matrix protein $(\mathrm{COMP})^{[12]}$. Thus, IL-1 $\beta$ stimulating $\mathrm{Wnt} / \beta$ catenin signal transduction in chondrocytes may lead to the development of OA, which can be verified by the use of dickkopf-1 (Dkk-1) protein ${ }^{[13]}$.

Platelet-rich plasma (PRP) contains a variety of growth factors, which can reduce the damage of many different cells ${ }^{[14]}$. Several growth factors of PRP were related to the cartilage repair. PRP can promote the healing of the injured soft tissue and the regeneration of ligaments and cartilage $^{[15]}$. In patients with the degenerative cartilage wear of the knee joint, the intra-articular injection of PRP can improve the symptoms of the knee joint ${ }^{[16]}$. In addition, PRP can promote the proliferation of rabbit auricle chondrocytes in vitro ${ }^{[17]}$. Our early study found that the PRP reduced the degenerative injury of articular cartilage in the rabbit knee joint OA model ${ }^{[18]}$. However, the mechanism of PRP reducing the cartilage pathological damage is still unclear.

In the current study, we hypothesized that PRP can inhibit the $\mathrm{Wnt} / \beta$-catenin signal in chondrocytes induced by IL-1 $\beta$. The purpose of this study was to investigate the effect of PRP on Wnt/ $\beta$-catenin signal transduction in chondrocytes stimulated by IL-1 $\beta$ in vitro and to provide a theoretical basis for the application of PRP in OA therapy.

\section{MATERIALS AND METHODS}

\section{Preparation of PRP:}

A total of $10 \mathrm{ml}$ venous blood was collected from the ear vein of New Zealand white rabbits (3 males and 2 females) by the Aghaloo method for the preparation of PRP. The blood was centrifuged at $215 \mathrm{~g}$ for $10 \mathrm{~min}$, the blood plasma above the buffy coat was collected and then centrifuged at $863 \mathrm{~g}$ for $10 \mathrm{~min}$, discard the supernatant and the remaining $0.8 \mathrm{ml}$ liquid was PRP $\left(1958.33 \pm 316.41 \times 10^{9} / \mathrm{L}\right.$, stored at $\left.-80^{\circ}\right)$. The volume of PRP extracted from each rabbit was $9.6 \pm 0.4 \mathrm{~mL}$.

\section{Culture and identification of chondrocytes:}

According to the existing research methods, the primary chondrocytes were isolated and cultured from the articular cartilage ${ }^{[19,20]}$. The main steps were as follows; open the rabbit knee joint, rinse clean, cut it into pieces, and digest it with $0.25 \%$ trypsin and $0.2 \%$ type II collagenase for $2-3 \mathrm{~h}$. After centrifugation, the cells were collected $\left(1000 \times \mathrm{g}, 37^{\circ}\right.$ for $\left.8 \mathrm{~min}\right)$ and resuspended in $5 \mathrm{~mL}$ Dulbecco modified Eagle medium (DMEM) containing $10 \%$ fetal bovine serum. The growth of chondrocytes was observed by a microscope. Chondrocytes were identified and counted after the proteoglycan staining with toluidine blue kit. In addition, CTX-II was immunostained with anti-CTXII primary antibody and horseradish peroxidase (HRP) labeled rabbit anti-goat secondary antibody (1:200) for chondrocyte identification and counting. Subculture was carried out with the specification of $1: 3\left(5 \times 10^{5} /\right.$ $\mathrm{mL})$. The cells were cultured in $5 \% \mathrm{CO}_{2}$ at $37^{\circ}$ for $48 \mathrm{~h}$ and the third to sixth generations of chondrocytes were used in the experiment. The cells were divided into five groups, the control group was only treated with normal saline and the other four groups were treated with IL$1 \beta$, the five groups were named as the control group, IL-1 $\beta$ group, PRP group, Dkk-1 group, and Dkk-1+PRP group. PRP group was treated with $100 \mathrm{x}$ diluted PRP solution for $1 \mathrm{~h}$, Dkk-1 group was treated with 100 $\mathrm{ng} / \mathrm{mL}$ Dkk-1 (inhibition of Wnt $/ \beta$-catenin signal) for $1 \mathrm{~h}^{[15]}$, Dkk-1+PRP group was treated with Dkk-1 and PRP for $1 \mathrm{~h}$, the control group and IL- $1 \beta$ group was treated with the same amount of normal saline for 1 h. Subsequently, IL-1 $\beta$, PRP, Dkk-1 and Dkk-1+PRP groups were all treated with recombinant human IL-1 $\beta$ $(10 \mu \mathrm{g} / \mathrm{mL})$ for $24 \mathrm{~h}^{[11]}$.

\section{Effect of PRP on the proliferation of chondrocytes:}

The chondrocytes in the logarithmic growth phase $\left(1 \times 10^{4}\right)$ were cultured in the medium containing $20 \%$ fetal bovine serum $\left(37^{\circ}, 5 \% \mathrm{CO}_{2}\right)$. After adhering to the wall, the cells were cultured in the serum-free DMEM for $24 \mathrm{~h}$. Then the PRP diluted $10 \mathrm{x}, 50 \mathrm{x}$, $100 \mathrm{x}$ or $150 \mathrm{x}$ was added to the medium and cultured for $96 \mathrm{~h}$. Then, the medium was changed and $20 \mu \mathrm{lmg} /$ $\mathrm{mL}$ MTT was added to the cells. After being cultured at $37^{\circ}$ for $4 \mathrm{~h}, 200 \mu \mathrm{L}$ solubilizing solution (10\% sodium dodecyl sulfate, $0.1 \mathrm{M}$ hydrochloric acid) was added and then the absorbance at $490 \mathrm{~nm}$ was measured. The experiment was repeated five times.

\section{Observation of the morphology of chondrocytes by transmission electron microscope (TEM):}

The chondrocytes were digested with $0.25 \%$ trypsin, centrifuged at $3000 \mathrm{rpm}$ for $15 \mathrm{~min}$ and mixed with $3 \%$ glutaraldehyde. After washing with Hank balanced salt 
solution for 3 times (10 min each time), the cells were treated with $1 \%$ osmium tetroxide for $2 \mathrm{~h}$, dehydrated with acetone and exposed to the embedding agent (Epon 812 ) overnight. After polymerization at $60^{\circ}$ for $24 \mathrm{~h}$, $50 \mathrm{~nm}$ thick slices were prepared and stained with uranyl acetate and lead citrate. The slices were observed by TEM.

\section{Detection of COMP and CTX-2 expression in chondrocytes:}

The chondrocyte culture medium was collected after 24 $\mathrm{h}$ of culture and the concentrations of COMP and CTXII were determined by enzyme-linked immunosorbent assay (Boster Bio).

\section{Detection of Wnt-1, $\beta$-catenin, and glycogen synthase} kinase (GSK)-3ß mRNA expression in chondrocytes:

The total RNA of chondrocytes was extracted by Trizol. The purity and concentration of the RNA were determined according to the absorbance of $\mathrm{OD}_{260 / 280}$ (Multiskan MK3 enzyme labeling instrument) and the cDNA was synthesized by the commercial kit. Real-time polymerase chain reaction (RT-PCR) was performed using the SYBR premix kit and FTC2000 reverse transcriptase-PCR system. The primers (Table 1) were synthesized by Invitrogen and $\beta$-actin was used as the internal reference. The $25 \mu \mathrm{L}$ amplification systems including $12.5 \mu \mathrm{L}$ mix, $0.5 \mu \mathrm{L}$ primer $\mathrm{F} / \mathrm{R}, 1.0 \mu \mathrm{L} \mathrm{cDNA}$, and $10.5 \mu \mathrm{L}$ doubledistilled water. The amplification conditions were as follows, $94^{\circ}$ pre-denaturation for $5 \mathrm{~min}, 30$ cycles of $94^{\circ}$ denaturation for $30 \mathrm{sec}, 56^{\circ}$ annealing for $45 \mathrm{sec}$, $72^{\circ}$ extending for $45 \mathrm{sec}$ and $72^{\circ}$ final extending for $10 \mathrm{~min}$. The primer designing followed the same standard and the concentration of the primer and $\mathrm{Mg}^{2+}$ were optimized according to the $2^{-\Delta \Delta C T}$ method ${ }^{[26]}$.

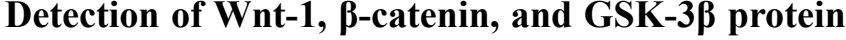 expression in chondrocytes:}

The total protein of chondrocytes was extracted by the mammalian protein extraction kit (Thermo Fisher
Scientific). The total protein concentration was measured using bicinchoninic acid (BCA) protein analysis kit, and the protein was separated by $10 \%$ SDS-PAGE (Shanghai Beyotime Biotechnology Co., Ltd.) and then transferred to the polyvinylidene difluoride (PVDF) membrane. After blocking the PVDF membrane with $5 \%$ skim milk, the PVDF membrane was incubated with the rabbit primary antibody of Wnt-1, $\beta$-catenin, or GSK-3 $\beta$ overnight at $4^{\circ}$ and then the HRP labeled goat anti-rabbit secondary antibody $(1: 1000)$ was incubated at room temperature for $2 \mathrm{~h}$. $\beta$-actin was used as the internal reference and electrochemiluminescence detection reagent was used for coloration. Quantity One software was used to quantify the bands.

\section{Statistical analysis:}

SPSS19.0 was used for statistical analysis. The quantitative data were expressed as average \pm standard error of mean. Single factor variance and t-test were used for statistical comparison. $\mathrm{p}<0.05$ was considered to be a significant difference.

\section{RESULTS AND DISCUSSION}

\section{Identification and morphology of chondrocytes:}

The number of the primary chondrocytes was rare, present as triangular, polygonal or irregular. After $24 \mathrm{~h}$ of culture, some chondrocytes have adhered to the surface of the culture dish (fig. 1A). The first generation of chondrocytes showed a better refractive effect than the primary chondrocytes, present as polygonal or irregular shape. After $5 \mathrm{~d}$ of culture, the cell density reached $80 \%$ and the chondrocytes formed a "slabstone" shape (fig. 1B). The second and third generation chondrocytes were fusiform or oval in shape and grew in clusters. The outline of the cells was obvious and the gap between the cells was large (fig. 1C and fig. 1D). When the chondrocytes were stained with toluidine blue, their nuclei were stained blue and purple granules were found in the cytoplasm and interspaces (fig. 1E). Immunohistochemistry

TABLE 1: PRIMER SEQUENCES USED IN THIS STUDY

\begin{tabular}{lccc}
\hline Protein gene & Order & Sequences & bp \\
\hline B-actin & Forward & 5'-GGAAATCTGTGCGTGACATTA-3' & 230 \\
& reverse & 5'-GGAGCAATGATCTTGATCTTC-3' & \\
GSK-3B & Forward & 5'-GCGTGAGGAGG-3' & 353 \\
& reverse & 5'-CAGTGGTGGAAATAAAGG-3' & \\
\multirow{2}{*}{ Wnt-1 } & Forward & 5'-CTGCGCCACACACAGAATTATTGTA-3' & 226 \\
& reverse & 5'-TTCACTGCATCTCTACTGATTCTT-3' & \\
B-actin & Forward & 5'-TGGCTCTACAGTCCGCCTAG-3' & 295 \\
& reverse & 5'-AGTGCGACGTGGACATCCG-3' \\
\hline
\end{tabular}




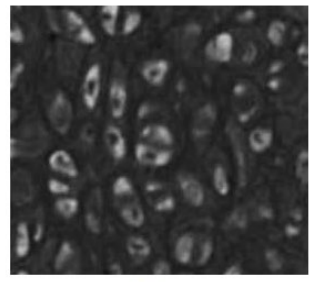

$\mathbf{A}$

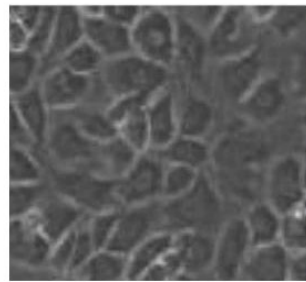

D

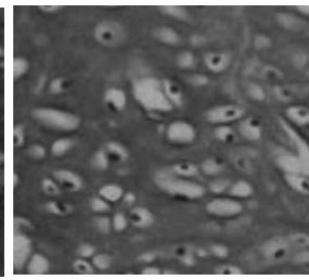

B

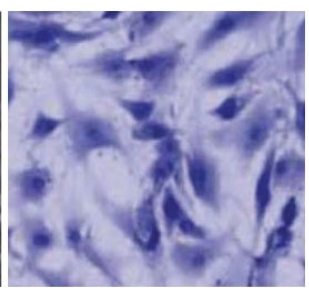

$\mathbf{E}$

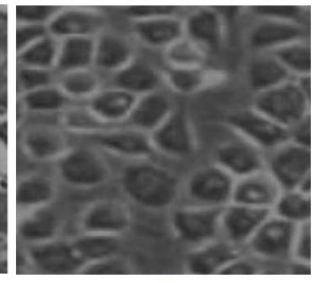

C

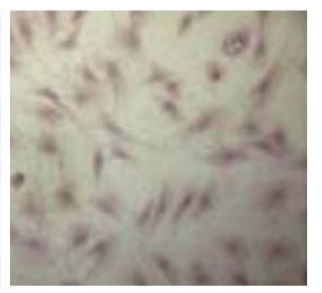

$\mathbf{F}$

Fig. 1: Morphology of chondrocytes under the microscope (400 x)

showed that the cytoplasmic staining of CTX-II was yellow (fig. 1F). Therefore, it is a typical characteristic that the chondrocytes can secrete CTX-II. The phenotype of articular chondrocytes remained stable in the third passage culture, the proliferation rate of the second and third passage was higher, most of the cells were approximately triangular or round and $80-85 \%$ of the cells adhered to the wall after $24 \mathrm{~h}$. In addition, CTX-II staining showed that the cells had the typical characteristics of chondrocytes, which indicated that they were suitable for further experiments.

\section{Effect of PRP on the proliferation of chondrocytes:}

Compared with the control group, four concentrations of PRP could significantly promote the proliferation of chondrocytes at all-time points $(24 \mathrm{~h}, 48 \mathrm{~h}, 72 \mathrm{~h}$ and $96 \mathrm{~h}, \mathrm{p}<0.05)$. At $24 \mathrm{~h}, 72 \mathrm{~h}$ and $96 \mathrm{~h}$, there was no significant difference among $100 \mathrm{x}, 50 \mathrm{x}$ and $10 \mathrm{x}$ PRP dilution groups ( $>0.05$, fig. 2A). However, at $24 \mathrm{~h}, 72 \mathrm{~h}$ and $96 \mathrm{~h}$, there were significant differences in chondrocyte proliferation between $10 \mathbf{x}$ and $150 \mathbf{x}$ PRP dilution groups $(\mathrm{p}<0.05), 50 \mathbf{x}$ and $150 \mathbf{x}$ PRP dilution groups $(p<0.05)$ and $100 \mathbf{x}$ and $150 \mathbf{x}$ PRP dilution groups ( $\mathrm{p}<0.05$, fig. $2 \mathrm{~A}$ ). The results of the absolute cell count showed similar results (fig. 2B). Therefore, $100 \mathrm{x}$ PRP dilutions were used in the subsequent experiment.

\section{Detection of COMP and CTX-2 in chondrocyte culture medium:}

The concentration of COMP in the IL- $1 \beta$ group was significantly higher than that in other groups, the control group, PRP group, Dkk-1 group and Dkk$1+$ PRP group $(\mathrm{p}<0.05$, fig. $3 \mathrm{~A})$ and the level of COMP in the control group was the lowest $(p<0.05)$. The level
A

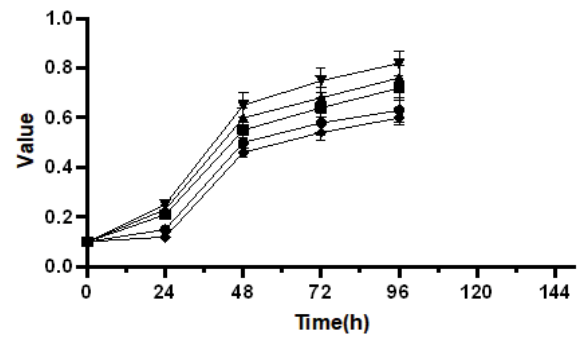

B

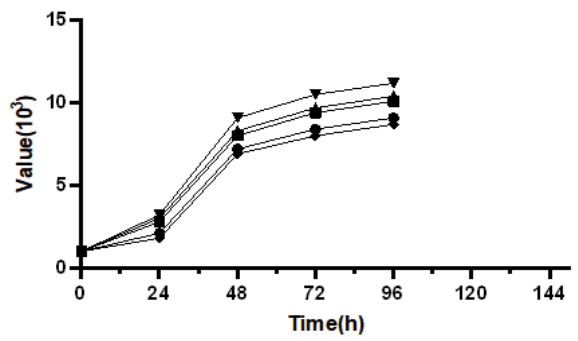

Fig. 2: Effect of PRP on the proliferation of chondrocytes Chondrocytes were cultured in the absence or presence of PRP $(10 \mathrm{x}, 50 \mathrm{x}, 100 \mathrm{x}$, and $150 \mathrm{x}$ PRP dilution) for $96 \mathrm{~h}$, and cell viability was evaluated by MTT assay (A) and cell count (B)

of COMP in the Dkk-1+PRP group was significantly lower than that in the Dkk-1 group $(\mathrm{p}<0.05$, fig. $3 \mathrm{~A})$. For the CTX-II level, similar results were also obtained (fig. 3B). The concentration of CTX-II in the IL-1 $\beta$ group was significantly higher than that in the control group ( $\mathrm{p}<0.05)$, PRP group, Dkk-1 group and Dkk$1+$ PRP group $(\mathrm{p}<0.05)$.

\section{Protein and mRNA expression of Wnt-1, $\beta$-catenin and GSK-3 $\beta$ in chondrocytes:}

The mRNA expression levels of Wnt- 1 and $\beta$-catenin in the IL-1 $\beta$ group were significantly higher than those in the control group $(\mathrm{p}<0.05$, fig. $4 \mathrm{~A})$. The mRNA expression levels of Wnt-1 and $\beta$-catenin in the PRP group, Dkk-1 group and Dkk-1+PRP group 
A

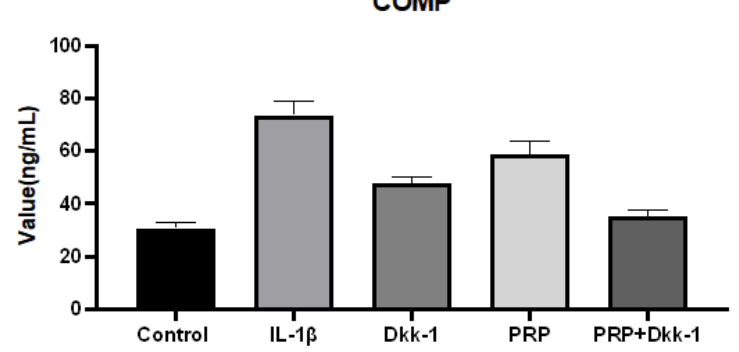

B

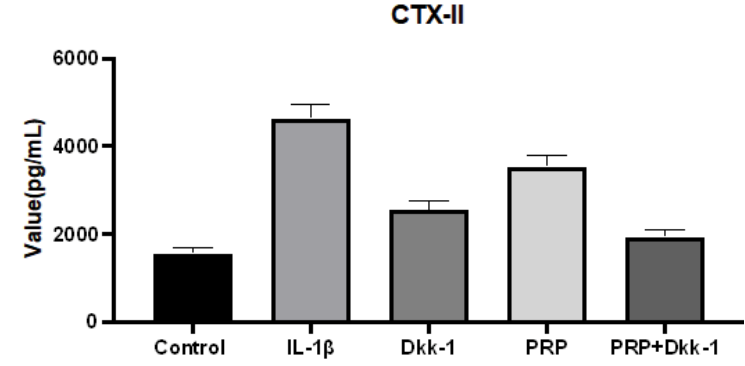

Fig. 3: Detection of COMP and CTX-2 in chondrocyte culture medium

were significantly lower than those in the IL- $1 \beta$ group $(p<0.05)$ and higher than those in the control group $(\mathrm{p}<0.05$, fig. $4 \mathrm{~A})$. In addition, the mRNA expression of GSK-3 $\beta$ in the IL-1 $\beta$ group was significantly lower than that in the control group, PRP group, Dkk-1 group and Dkk-1+PRP group and the control group was the most. The expression of GSK-3 $\beta$ mRNA in the Dkk$1+$ PRP group was significantly higher than that in the Dkk-1 group ( $\mathrm{p}<0.05$, fig. $4 \mathrm{~A}$ ). The protein expression levels of Wnt- 1 and $\beta$-catenin in the IL- $1 \beta$ group were significantly higher than those in the control group, PRP group, Dkk-1 group and Dkk-1+PRP group $(\mathrm{p}<0.05$, fig. 4B). The protein levels of Wnt-1 and $\beta$-catenin in the Dkk-1+PRP group were significantly lower than those in the Dkk-1 group ( $p<0.05$, fig. $4 \mathrm{~B}$ ). The protein expression of GSK-3 $\beta$ in the IL- $1 \beta$ group was significantly lower than that in the control group, PRP group, Dkk-1 group and Dkk-1+PRP group $(\mathrm{p}<0.05$, fig. 4B).

The purpose of this study was to investigate the effect of PRP on Wnt/ $\beta$-catenin signal transduction in rabbit chondrocytes. We found that PRP promoted the proliferation of rabbit chondrocytes. In addition, chondrocytes activated by IL- $1 \beta$ showed the abnormal ultrastructure, which was alleviated after the treatment with PRP, Dkk-1 or Dkk-1 PRP. The expression of CTX-2 and COMP in the IL-1 $\beta$ group was higher than that in the control group, PRP group, Dkk-1 group and Dkk-1+PRP group, which means that PRP and Dkk-1 alone or in combination can protect the chondrocytes from apoptosis. In addition, IL-1 $\beta$ group had higher mRNA and protein expression of Wnt- 1 and $\beta$-catenin and lower expression of GSK-3 $\beta$ than the control group. The enhancement of the $\mathrm{Wnt} / \beta$-catenin signal induced by IL- $1 \beta$ was partially reversed by PRP, Dkk1 or their combination. These data suggest that PRP may protect the chondrocytes by inhibiting the Wnt/ $\beta$ catenin signal.

The knee joint was a common sight of $\mathrm{OA}^{[6]}$, cartilage degeneration will affect the physiological function of chondrocytes $^{[21]}$. The classical Wnt/ $\beta$-catenin pathway regulates the bone metabolism and bone formation and the development and remodeling of cartilage tissue, which was related to $\mathrm{OA}^{[8,22]}$. The interleukin cytokine family was a classical regulator of inflammation and was considered to play an important role in the development of rheumatoid arthritis ${ }^{[23]}$. Many studies have reported that the expression of IL- $1 \beta$ in OA was higher than that in the normal joints ${ }^{[11]}$. It has been suggested that during OA, the expression of IL- $1 \beta$ was up-regulated by the granulosa cells and macrophages secrete granulocytemacrophage colony-stimulating factor (GM-CSF), which up-regulates the matrix metalloproteinases in cartilage and synovium and leads to chondrocyte death $^{[24,25]}$. IL-1 $\beta$ induces cartilage matrix degradation ${ }^{[9]}$, which can be prevented by the inhibition of $\mathrm{Wnt} / \beta$ catenin signal transduction ${ }^{[10]}$. Therefore, IL-1 $\beta$ was thought to activate $\mathrm{Wnt} / \beta$-catenin signal and induce the apoptosis of chondrocytes ${ }^{[11]}$. In this study, we cultured rabbit knee chondrocytes and stimulated them with IL-

A

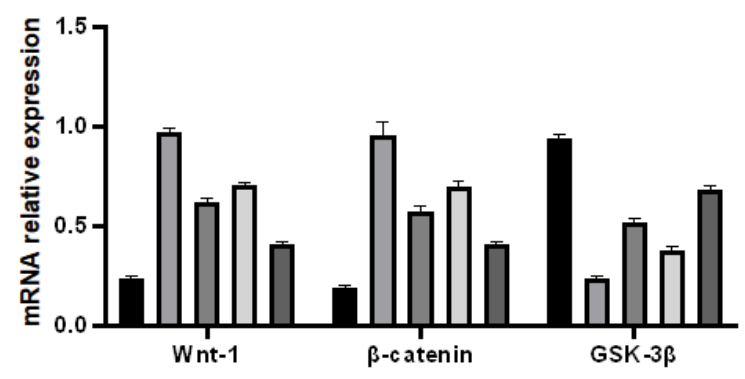

B

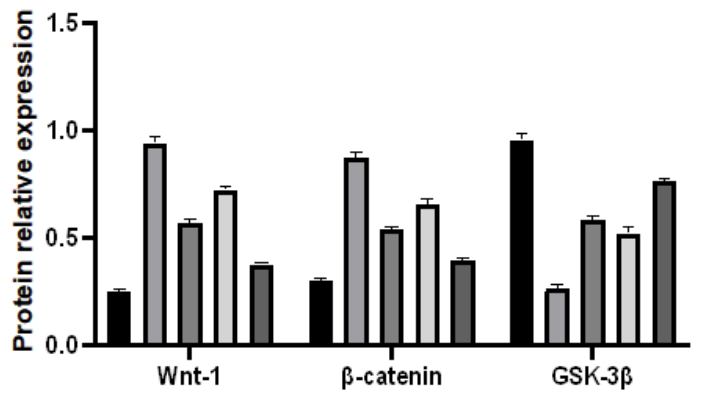

Fig. 4: Protein and mRNA expression of Wnt-1, $\beta$-catenin, and GSK-3ß in chondrocytes 
$1 \beta$ to construct a cell model of $\mathrm{Wnt} / \beta$-catenin signal transduction. When the chondrocytes were treated with IL-1 $\beta$, they showed contraction, irregular shape and fewer microvilli on the surface of the cell membrane, uneven high electron density areas in the cytoplasm, rER expansion, obvious pyknosis, irregular nuclear shape and many lipid droplets and vacuoles. This result was consistent with the previous studies ${ }^{[26]}$.

Our previous studies found that PRP alleviated the effect of IL- $1 \beta$ in synovial fluid ${ }^{[22]}$, which was consistent with the current observation that PRP alleviated the an ultrastructural abnormality of chondrocytes induced by IL-1 $\beta$ and reduced apoptosis (indirectly represented by a decrease in the content of COMP and CTX-II in the culture medium). We found that PRP enhances the activity of chondrocytes, which was consistent with the previously reported study that PRP protects cells/tissues from damage. PRP contains a variety of growth factors, including platelet-derived growth factor (PDGF), vascular endothelial growth factor (VEGF) and transforming growth factor- $\beta$ (TGF- $\beta)^{[27,28]}$. PRP can treat skeletal muscle injury ${ }^{[24]}$ and release the growth factors involved in cartilage repair to promote cartilage regeneration ${ }^{[28]}$. Intra-articular injection of PRP can improve the International Knee Documentation Committee (IKDC) score of patients with knee cartilage degeneration ${ }^{[20]}$, while PRP can promote the proliferation of rabbit auricle chondrocytes in vitro ${ }^{[21]}$. Our current observations are also consistent with our early conclusion that PRP can reduce the degenerative changes of articular cartilage ${ }^{[22]}$. Therefore, PRP may develop into a new therapy to inhibit the cartilage degeneration in OA. In this study, the effect of PRP was concentration dependent. The promoting effect of PRP $100 \mathrm{x}$ diluent on chondrocyte proliferation was similar to that of $10 \mathrm{x}$ and $50 \mathrm{x}$ dilution, but better than $150 \mathrm{x}$ diluent, so $100 \mathrm{x}$ diluent was used in the subsequent experiment.

Early studies on OA chondrocytes showed that the low dose of IL-1 $\beta(10 \mu \mathrm{g} / \mathrm{mL})$ could activate the $\mathrm{Wnt} / \beta$-catenin pathway ${ }^{[29]}$. Similarly, we observed that the mRNA and protein expression of Wnt-1 and $\beta$-catenin were up-regulated, while the mRNA and protein expression of GSK-3 $\beta$ were down-regulated in chondrocytes stimulated by IL-1 $\beta$. In addition, these changes induced by IL- $1 \beta$ could be attenuated by Dkk1 , an inhibitor of the Wnt/ $\beta$-catenin pathway. Wnt $/ \beta$ catenin signal plays an important role in the growth, differentiation and maturation of chondrocytes ${ }^{[26]}$. The overexpression of Wnt-1 protein leads to the continuous expression of $\beta$-catenin, which leads to the proliferation, hypertrophy and end-stage differentiation of chondrocytes. In addition, when Wnt-1 protein was overexpressed, the activity of GSK-3 $\beta$ was inhibited, which in turn leads to the accumulation of $\beta$-catenin in chondrocytes ${ }^{[9]}$. The mRNA and protein expression of $\beta$-catenin in chondrocytes of the arthritis model was significantly higher than that of the normal chondrocytes ${ }^{[30]}$. Overexpression of $\beta$-catenin stimulates the chondrocytes to secrete matrix metalloproteinases, resulting in the degradation of cartilage matrix and damage of normal physiological activity of chondrocytes ${ }^{[31]}$. Our findings are consistent with the view that the enhancement of the $\mathrm{Wnt} / \beta$-catenin signal transduction contributes to the chondrocyte injury during OA. This can be further studied by using the established inhibitors such as Dkk-1 to inhibit the Wnt/ $\beta$-catenin signal transduction ${ }^{[15]}$. It is worth noting that Dkk-1 alleviated the ultrastructural abnormality of chondrocytes induced by IL- $1 \beta$ and decreased the expression of COMP and CTX-II, indicating that the level of cell injury/apoptosis was low. In summary, these data showed that IL- $1 \beta$ can activate $W n t / \beta$ catenin signal in chondrocyte injury.

This study found that PRP regulates the ultrastructural changes of chondrocytes, apoptosis (COMP and CTXII) and the expression of Wnt-1, $\beta$-catenin, GSK-3 $\beta$, and Dkk-1. This suggests that PRP inhibits Wnt/ $\beta$-catenin signal transduction in the chondrocytes activated by IL$1 \beta$, which protects cells from excessive damage after exposure to IL-1 $\beta$. It is worth noting that the effect of PRP on the concentration of COMP and CTX-II medium and on the mRNA and protein expression of Wnt-1, $\beta$-catenin and GSK-3 $\beta$ was not as great as that of PRP and Dkk-1 combination. This indicates that the inhibition of Wnt/ $\beta$-catenin signal transduction by PRP $(100 \mathrm{x})$ is only partial. However, our data showed that PRP can inhibit the Wnt/ $\beta$-catenin pathway and protect chondrocytes from injury after IL- $1 \beta$ treatment. At present, there is no clinical drug that can reverse the process of $\mathrm{OA}^{[2]}$. Our results suggest that PRP therapy may develop into a new method for the prevention and treatment of OA.

\section{Authors' contributions:}

QX Zhang and HG Bao conceived and designed the experiments; L Wang and YN Si performed the experiments; XH Zuo, N Sun and P Xie analyzed the data and wrote the paper. 


\section{Acknowledgements:}

This work was supported by the National Natural Science Foundation of China (No. 81873954). XH Zuo, $\mathrm{N}$ Sun and $\mathrm{P}$ Xie are contributed equally to this work, QX Zhang and $\mathrm{HG}$ BAO are considered co-corresponding authors.

\section{Conflicts of interest:}

The authors report no conflicts of interest.

\section{REFERENCES}

1. Neogi T, Zhang Y. Epidemiology of osteoarthritis. Rheum Dis Clin 2013;39(1):1-9.

2. Deveza LA, Melo L, Yamato TP, Mills K, Ravi V, Hunter DJ. Knee osteoarthritis phenotypes and their relevance for outcomes: a systematic review. Osteoarthr Cartil 2017;25(12):1926-41.

3. Reginster JY, Reiter-Niesert S, Bruyere O, Berenbaum $\mathrm{F}$, Brandi ML, Branco J, et al. Recommendations for an update of the 2010 European regulatory guideline on clinical investigation of medicinal products used in the treatment of osteoarthritis and reflections about related clinically relevant outcomes: expert consensus statement. Osteoarthr Cartil 2015;23(12):2086-93.

4. Cutolo M, Berenbaum F, Hochberg M, Punzi L, Reginster JY. Commentary on recent therapeutic guidelines for osteoarthritis. Arthritis Rheum 2015;44(6):611-7.

5. Liebs TR, Berger S. Termination of reimbursement of arthroscopy in osteoarthritis of the knee: Is this decision based on scientific grounds?. Z Orthop Unfall 2017;155(4):417-28.

6. Sandy JD, Chan DD, Trevino RL, Wimmer MA, Plaas A. Human genome-wide expression analysis reorients the study of inflammatory mediators and biomechanics in osteoarthritis. Osteoarthr Cartil 2015;23(11):1939-45.

7. Wei T, Kulkarni NH, Zeng QQ, Helvering LM, Lin X, Lawrence $\mathrm{F}$, et al. Analysis of early changes in the articular cartilage transcriptisome in the rat meniscal tear model of osteoarthritis: pathway comparisons with the rat anterior cruciate transection model and with human osteoarthritic cartilage. Osteoarthr Cartil 2010;18(7):992-1000.

8. Zhou Y, Wang T, Hamilton JL, Chen D. Wnt/ $\beta$-catenin signaling in osteoarthritis and in other forms of arthritis. Curr Rheumatol Rep 2017;19(9):1-8.

9. Yuasa T, Otani T, Koike T, Iwamoto M, Enomoto-Iwamoto $\mathrm{M}$. Wnt/ $\beta$-catenin signaling stimulates matrix catabolic genes and activity in articular chondrocytes: its possible role in joint degeneration. Lab Investig 2008;88(3):264-74.

10. Landman EB, Miclea RL, van Blitterswijk CA, Karperien M. Small molecule inhibitors of WNT/ $\beta$-catenin signaling block IL- $1 \beta$-and TNF $\alpha$-induced cartilage degradation. Arthritis Res Ther 2013;15(4):1-1.

11. Wang F, Wu L, Li L, Chen S. Monotropein exerts protective effects against IL-1 $\beta$-induced apoptosis and catabolic responses on osteoarthritis chondrocytes. Int Immunopharmacol 2014;23(2):575-80.

12. De Ceuninck F, Sabatini M, Pastoureau P. Recent progress toward biomarker identification in osteoarthritis. Drug Discov
2011;16(9-10):443-9.

13. Zhang ZC, Liu JX, Shao ZW, Pu FF, Wang BC, Wu Q, et al. In vitro effect of microRNA-107 targeting Dkk-1 by regulation of Wnt/beta-catenin signaling pathway in osteosarcoma. Medicine (Baltimore) 2017;96(27):7245.

14. Chiavaras MM, Jacobson JA, Carlos R, Maida E, Bentley $\mathrm{T}$, Simunovic $\mathrm{N}$, et al. Impact of platelet rich plasma Over alternative therapies in patients with lateral epicondylitis (IMPROVE): protocol for a multicenter randomized controlled study: a multicenter, randomized trial comparing autologous platelet-rich plasma, autologous whole blood, dry needle tendon fenestration, and physical therapy exercises alone on pain and quality of life in patients with lateral epicondylitis. Acad Radiol 2014;21(9):1144-55.

15. Dietrich F, Hammerman M, Blomgran P, Tätting L, Bampi VF, Silva JB, et al. Effect of platelet-rich plasma on rat Achilles tendon healing is related to microbiota. Acta orthop 2017;88(4):416-21.

16. Kon E, Buda R, Filardo G, Di Martino A, Timoncini A, Cenacchi $\mathrm{A}$, et al. Platelet-rich plasma: intra-articular knee injections produced favorable results on degenerative cartilage lesions, Knee Surg. Sports Traumatol Arthrosc 2010;18(4):472-9.

17. Manafi K, Kaviani-Far K, Moradi M, Manafi A, Manafi F. Effects of platelet-rich plasma on cartilage grafts in rabbits as an animal model. World J Plast Surg 2012;1(2):91-8.

18. Wu J, Zhang Z, Qin XX, Cai XH, Hu F. Platelet-rich-plasma alleviates pathological symptoms in a rabbit model of osteoarthritis. Int J Clin Exp Med 2016;9(11):21038-47.

19. Freymiller EG, Aghaloo TL. Platelet-rich plasma: ready or not? J Oral Maxillofac Surg 2004;62(4):484-8.

20. Khoshfetrat AB, Kino-Oka M, Takezawa Y, Yamamoto T, Sugawara K, Taya M. Seeding density modulates migration and morphology of rabbit chondrocytes cultured in collagen gels. Biotechnol Bioeng 2009;102(1):294-302.

21. Yu SM, Kim SJ. Salinomycin causes dedifferentiation via the extracellular signalregulated kinase (ERK) pathway in rabbit articular chondrocytes. J Pharmacol Sci 2015;127(2):196-202.

22. Lu YC, Song J, Cho HY, Fan G, Yokoyama KK, Chiu R. Cyclophilin a protects Peg3 from hypermethylation and inactive histone modification. J Biol Chem 2006;281(51):39081-7.

23. Hosnijeh FS, Runhaar J, van Meurs JB, Bierma-Zeinstra SM. Biomarkers for osteoarthritis: can they be used for risk assessment? A systematic review. Maturitas 2015;82(1):36-49.

24. Rojas-Ortega M, Cruz R, Vega-Lopez MA, Cabrera-Gonzalez M, Hernandez JM, Lavalle-Montalvo C, et al. Exercise modulates the expression of IL-1beta and IL-10 in the articular cartilage of normal and osteoarthritis-induced rats. Pathol Res Pract 2015;211(6):435-43.

25. Weng LH, Wang CJ, Ko JY, Sun YC, Su YS, Wang FS. Inflammation induction of Dickkopf-1 mediates chondrocyte apoptosis in osteoarthritic joint. Osteoarthr Cartil 2009; 17(7):933-43.

26. Zhang Y, Morgan BJ, Smith R, Fellows CR, Thornton C, Snow $\mathrm{M}$, et al. Platelet-rich plasma induces post-natal maturation of immature articular cartilage and correlates with LOXL1 activation. Sci Rep 2017;7(1):3699.

27. Gibson AL, Mingalone CKH, Foote AT, Uchimura T, Zhang M, Zeng L. Wnt7a inhibits IL-1beta induced catabolic gene expression and prevents articular cartilage damage in experimental osteoarthritis. Sci Rep 2017;7(1):1-6. 
28. Takamatsu A, Ohkawara B, Ito M, Masuda A, Sakai T, Ishiguro $\mathrm{N}$, et al. Verapamil protects against cartilage degradation in osteoarthritis by inhibiting Wnt/ $\beta$-catenin signaling. PloS one 2014;9(3):e92699.

29. Yuan X, Liu H, Huang H, Liu H, Li L, Yang J, Shi W, Liu W, $\mathrm{Wu} \mathrm{L}$. The key role of canonical $\mathrm{Wnt} / \beta$-catenin signaling in cartilage chondrocytes. Curr Drug Targets 2016;17(4):475-84.

30. Bouaziz W, Funck-Brentano T, Lin H, Marty C, Ea HK, Hay $\mathrm{E}$, et al. Loss of sclerostin promotes osteoarthritis in mice via $\beta$-catenin-dependent and-independent Wnt pathways. Arthritis Res Ther 2015;17(1):1.

31. Marmotti A, Rossi R, Castoldi F, Roveda E, Michielon G,
Peretti GM. PRP and articular cartilage: a clinical update. Biomed Res Int 2015:542502.

This is an open access article distributed under the terms of the Creative Commons Attribution-NonCommercial-ShareAlike 3.0 License, which allows others to remix, tweak, and build upon the work non-commercially, as long as the author is credited and the new creations are licensed under the identical terms

This article was originally published in a special issue, "Trends in Therapeutic Management of Various Clinical Conditions II" Indian J Pharm Sci 2021:83(2)Spl issue;98-105 